\title{
Análise comparativa de laringectomias parciais com e sem realização de traqueostomia
}

\section{Comparative analysis of partial laringectomies with and without tracheostomy}

\author{
Henrique O. O. Costa ${ }^{1}$ André C. Duprat ${ }^{2}$, \\ Claudia A. Eckley, Samantha R. F. Dutra ${ }^{4}$, \\ Carolina M. Cavalcanti
}

Palavras-chave: laringectomia parcial, traqueostomia. Key words: partial laryngectomy, tracheostomy.

\section{Resumo / Summary}

\begin{abstract}
A laringectomia parcial é uma alternativa no tratamento do câncer de laringe. Este tipo de cirurgia tem vantagens na qualidade de vida do paciente, pois permite a não realização de traqueostomia permanente. Objetivo: Comparar os resultados das laringectomias parciais com e sem realização de traqueostomia. Forma de estudo: Caso-controle. Material e Método: Foram estudados 22 pacientes submetidos a laringectomias parciais, sendo 11 sem traqueostomia e 11 com traqueostomia no intra-operatório. Resultados: O grupo de pacientes sem traqueostomia apresentou vantagens quanto ao tempo de cirurgia, de internação e de permanência da sonda nasoenteral. Conclusão: A laringectomia parcial sem traqueostomia é um procedimento vantajoso para o paciente, diminuindo a morbidade e não apresentando diferença quanto a positividade das margens das lesões.
\end{abstract}

\begin{abstract}
$\mathbf{P}$ artial laryngectomy is an alternative in the treatment of laryngeal cancer. This kind of surgery has advantages in quality of life, because it allows procedure without permanent tracheostomy. Aim: Compare results of partial laryngectomies with and without tracheostomy. Study design: Case-control. Material and Method: Twentytwo patients submitted to partial laryngectomy were analyzed, 11 without tracheostomy and 11 with tracheostomy in the same surgical act. Results: The group of patients without tracheostomy shows advantages in the matter of time of surgery, hospitalization and use of nasoenteral tube. Conclusion: The laryngectomy without tracheostomy is an advantageous procedure lowing morbidity and showing no difference in the positivity of lesion bounds.
\end{abstract}

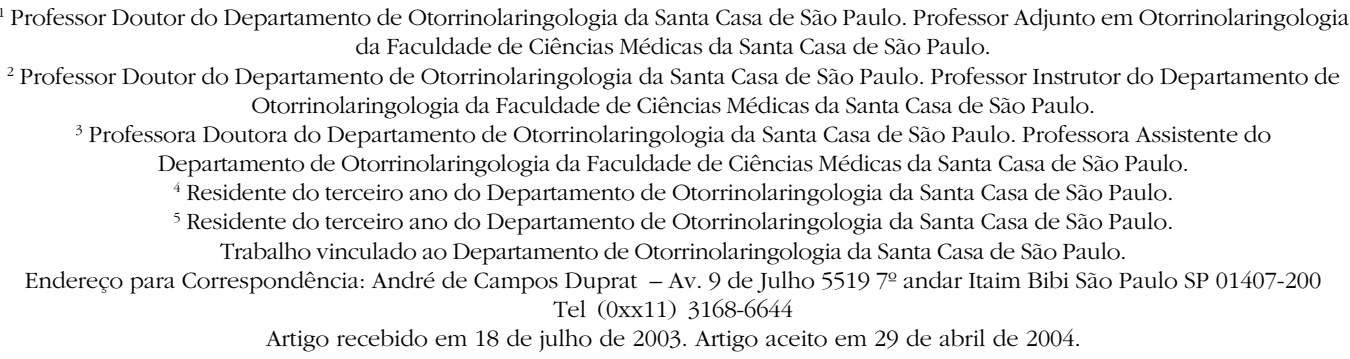




\section{INTRODUÇÃO}

As cirurgias parciais vêm sendo utilizadas cada vez mais no tratamento do câncer de laringe, mostrando melhores resultados em relação à qualidade de vida e resultados semelhantes em relação ao controle local da doença $a^{1,2}$. A realização de traqueostomia em pacientes submetidos a laringectomias é uma segurança na manutenção da permeabilidade das vias aéreas superiores. No entanto, pode estar relacionada a uma maior morbidade, como fonte de contaminação, retardar a introdução de dieta por via oral, além de aumentar o tempo cirúrgico. Frente a estas hipóteses, passamos a realizar no nosso serviço as laringectomias parciais sem realizar traqueostomia, e não nos deparamos com qualquer problema em relação ao controle da via aérea. O objetivo deste trabalho é realizar um estudo comparando os resultados das laringectomias parciais com e sem realização de traqueostomia, definindo as vantagens e desvantagens da não realização de cada procedimento.

\section{MATERIAL E MÉTODO}

De Janeiro de 2001 a Maio de 2002 foram tratados cirurgicamente 11 casos de tumores glóticos, com diagnóstico anatomopatológico de carcinoma espinocelular, no Serviço de Laringe do Departamento de Otorrinolaringologia da Santa Casa de São Paulo. Estes pacientes foram submetidos a laringectomia vertical frontolateral sem traqueostomia no intraoperatório e reconstrução com músculo esternohióideo. Alguns pacientes, com tumores glóticos T2 ou T3, foram submetidos a laringectomia frontolateral ampliada com retirada de tecidos da supraglote e ou da aritenóide. No presente trabalho, esses casos foram avaliados quanto ao seguimento clínico cirúrgico e os dados foram obtidos de forma retrospectiva através da análise dos prontuários médicos, que se encontram aos cuidados do Serviço de Arquivo da Santa Casa de São Paulo. Foi preenchido protocolo de seguimento de todos os casos, a partir dos quais foram extraídos os dados considerados de importância para análise conjunta do grupo e para discussão com os da literatura.

Para traçar um paralelo de comparação, buscamos mais 11 casos de pacientes com tumores glóticos, com diagnóstico anatomopatológico de carcinoma espinocelular. Estes pacientes foram submetidos a laringectomia vertical frontolateral, com traqueostomia intra-operatória e reconstruídos através da mesma técnica com o músculo esterno-hióideo. A laringectomia frontolateral foi ampliada nos casos T2 ou T3. Este grupo controle foi admitido no serviço de Março de 1998 até Novembro de 2000 e foram selecionados de forma aleatória, segundo os primeiros prontuários disponíveis para análise no arquivo. Os casos submetidos a traqueostomia pré-operatória foram excluídos deste trabalho. O grupo A (controle) foi então formado pelos pacientes submetidos a traqueostomia, e o grupo B (caso) foi composto pelos pacientes sem traqueostomia.

Os dados analisados foram: tempo cirúrgico, dias de internação, números de dias com sonda nasoenteral (SNE), e o acometimento das margens do tumor detectados na biópsia de congelação. As margens consideradas foram as enviadas após a remoção da peça, sendo considerado positivo o caso no qual pelo menos uma margem estivesse comprometida. Os casos com margem positiva foram submetidos a uma ressecção de margem complementar no mesmo momento cirúrgico, não sendo considerado o resultado da margem complementar na comparação entre os dois grupos. As complicações durante o período de internação foram descritas.

No grupo A (11 pacientes), a idade média foi de 60 anos e 3 meses sendo a mínima de 31 anos e a máxima de 76 anos. Foram selecionados 10 do sexo masculino e 1 do sexo feminino. O estadiamento (TNM) dos pacientes foi Tl b para 4 casos, T2 para 4 casos, T3 para 3 casos e T4 para nenhum caso, sendo todos N0 Mx. É importante ressaltar que o tempo médio de traqueostomia no grupo B foi de 23,45 dias entre os 9 pacientes que ficaram provisoriamente com traqueostomia, sendo o mínimo de 14 dias. Dois pacientes deste grupo ficaram com traqueostomia definitiva.

No grupo B (11 pacientes), a idade média foi de 59 anos e 7 meses, variando de 51 anos a 77 anos. Em relação ao sexo foram avaliados 9 pacientes do sexo masculino e 2 do sexo feminino, estabelecendo uma proporção de 4.5 do sexo masculino para 1 do sexo feminino. O estadiamento (TNM) dos pacientes foi: Tlb para 3 casos, T2 para 3 casos, T3 para 4 casos e T4 para 1 caso, todos NOMx.

\section{RESULTADOS}

Grupo A (com traqueostomia):

- O tempo de internação médio foi de 9 dias, variando de 4 dias a 14 dias.

- O tempo de sonda nasoenteral médio foi de 9.27 dias, variando de 4 dias a um tempo máximo de 30 dias.

- O tempo cirúrgico médio foi de 3 horas e 48 minutos, variando de 1 hora e 45 minutos a 4 horas e 40 minutos.

- Em relação às margens cirúrgicas, dois pacientes apresentaram pelo menos uma margem comprometida e 9 tiveram as margens livres.

- Não observamos neste grupo nenhuma complicação durante o período de internação.

Grupo B (sem traqueostomia):

- O tempo de internação médio foi de 6.2 dias variando de 3 a 15 dias.

- O tempo médio de permanência da sonda nasoenteral foi de 4 dias, variando de 1 dia a até no máximo 7 meses 
(um único paciente). Este caso, no entanto, não foi considerado por tratar-se de um problema isolado, no qual outros fatores interferiram na manutenção da sonda.

- O tempo cirúrgico médio foi de 2 horas e 49 minutos, sendo o menor tempo Ih e 55 min e o maior 5 horas.

- Em relação às margens cirúrgicas, três pacientes apresentaram pelo menos uma margem positiva na congelação e 8 apresentaram margens livres. As margens comprometidas na congelação foram submetidas à ressecção de margem complementar, no mesmo tempo cirúrgico.

- Como complicação, observamos 5 pacientes com enfisema subcutâneo, o qual teve início no segundo dia pós-operatório. Estes pacientes apresentavam estadiamento glótico T1b (1caso), T2 (2 casos), T3 (1 caso) e T4 (1 caso).

\section{DISCUSSÃ̃O}

A opção pela cirurgia conservadora com preservação parcial da laringe tem sido o tratamento de escolha no nosso serviço, uma vez que permite o controle efetivo do sítio da lesão e melhor resultado funcional ${ }^{3}$. Alguns autores defendem as cirurgias parciais da laringe apenas para os casos de estadiamento Tl e T2 ${ }^{4}$. Em nossa casuística, dos 22 pacientes analisados, realizamos cirurgias parciais em 7 casos com estadiamento T3 e 1 caso com estadiamento T4.

Em relação ao tempo de internação, os pacientes do grupo B (sem traqueostomia) apresentaram uma média de 6.2 dias e o grupo B, 9 dias. A redução no tempo de internação é um fator importante a ser considerado frente ao custo e ao pequeno número de leitos disponíveis dentro de um serviço público. Os pacientes do grupo B tiveram o tempo de internação prolongado em alguns casos devido ao enfisema subcutâneo, que ocorreu em 5 pacientes no segundo dia de pós-operatório. Todos os casos tiveram resolução espontânea, sendo controlado com repouso e curativo compressivo cervical. Esta complicação reflete a importância do fechamento cuidadoso da parede anterior da laringe, do curativo cervical compressivo e do repouso. Esta complicação foi observada em pacientes T1b, T2, T3 e T4, portanto não há uma relação evidente do grau da ressecção com a presença desta complicação. Nenhum paciente do grupo com traqueostomia teve esta complicação. A traqueostomia permite o escape do ar pelo seu orifício, impedindo a ocorrência do enfisema subcutâneo.

O grupo B teve um tempo médio com a SNE de 4 dias contra 9,27 dias do grupo A. A traqueostomia prejudica a elevação da laringe, dificultando a abertura do esfíncter superior do esôfago, e um fechamento menos efetivo do vestíbulo laríngeo contra a epiglote, expondo o paciente a um maior risco de aspiração. Ao mesmo tempo em que a traqueostomia permite uma melhor higienização pulmonar, expõe o pulmão a um maior risco de aspiração. A retirada precoce da cânula de traqueostomia facilita a movimentação traqueo-esofágica restabelecendo a deglutição mais rapidamente ${ }^{5,6}$.

O tempo cirúrgico em média foi reduzido em uma hora. O grupo A, ao não ser submetido a traqueostomia, não teve a necessidade de realizar ligadura do istmo da tireóide, permitindo uma economia no tempo cirúrgico ainda maior. Este grupo de pacientes, em geral, apresenta limitações pulmonares associadas ao transtorno laríngeo, portanto, ao reduzir o tempo cirúrgico diminuímos a exposição do paciente a uma maior morbidade cirúrgica. Pacientes com um maior risco cirúrgico devem ser considerados na utilização desta técnica.

Em relação às margens da lesão, observamos três margens comprometidas nos pacientes sem traqueostomia, e nos pacientes com traqueostomia, tivemos dois casos. É importante frente a uma margem comprometida a possibilidade de complementar a ressecção das margens a fim de realizar uma exérese controlada da lesão ${ }^{7}$. Na nossa prática, a maior dificuldade foi a manipulação da área a ser ressecada nos casos sem traqueostomia., o que é um fator importante a ser considerado frente a uma cirurgia oncológica. A presença da cânula orotraqueal limita a visualização da porção posterior da lesão, o que poderia levar a um prejuízo na definição das margens do tumor. No nosso trabalho observamos resultados semelhantes entre os dois grupos em relação à positividade da margem. Pacientes com margens comprometidas teriam um pior prognóstico oncológico ${ }^{8,9}$. Consideramos este procedimento mais trabalhoso, no entanto sem nenhuma interferência no resultado final. A dificuldade em definir o acometimento das margens não mostra relação com a técnica utilizada. No entanto, nos casos com extensão tumoral para a região interaritenoídea, esta técnica deve ser usada com cautela, pois a cânula orotraqueal pode dificultar a manipulação desta área e interferir no prognóstico do paciente.

A não realização da traqueostomia é uma alternativa nas laringectomias parciais. Os casos a serem submetidos a esta técnica sem traqueostomia devem ser bem selecionados.

Pacientes com lesão na porção posterior da laringe podem necessitar de uma maior manipulação da área tumoral às custas da cânula orotraqueal no campo cirúrgico. Acreditamos que estes casos tenham maior benefício com a traqueostomia. Já pacientes com lesões que não acometam o processo vocal e ou a região interaritenoidea devem ser considerados candidatos para a técnica sem traqueostomia. A redução do tempo cirúrgico, do tempo de internação, assim como maior agilidade na reabilitação da deglutição, podem trazer maior benefício aos pacientes, especialmente aqueles com maior morbidade clínica. No entanto, um maior tempo de seguimento destes casos é necessário para permitir uma análise real do controle oncológico destes pacientes. 


\section{CONCLUSÃO}

A laringectomia parcial com utilização do músculo esternohióideo para reconstrução sem realização de traqueostomia é um procedimento que permite a redução do tempo de internação, assim como no tempo de uso da SNE, não interferindo na positividade das margens da lesão. Trabalhos com um tempo maior de seguimento são necessários para definir a efetividade do controle tumoral com esta técnica.

\section{REFERÊNCIAS BIBLIOGRÁFICAS}

1. Weinstein GS, El-Sawy MM, Ruiz C, Dooley P, Chalian A, El-Sayed MM, Goldberg A. Laryngeal preservation with supracricoid partial laryngectomy results in improved quality of life when compared with total laryngectomy. Laryngoscope 2001;111:191-9.

2. Muller R. Quality of life of patients with laryngeal carcinoma: post treatment study. Eur Arch Otorhinolaryngol 2001; 258(6):27680 .
3. Costa $\mathrm{H}$ et al. Cirurgia conservadora da laringe em tumores glóticos T3 e T4. Experiência de 10 anos. Rev Bras Otorrin 2001; 67:35762 .

4. Giovanni A et al. Partial frontolateral laryngectomie with epiglotis reconstruction for management of early stage glotic carcinoma Laryngoscopie 2001; 11(4):663-8.

5. Shenoy AM, Kumar SS, Nanjundappa, Prasad S, Premalatha BS. Supracricoid laryngectomy with cricohyoidopexy: a clinico oncological and functional experience. Indian J Cancer 2000; 37(2-3):67-73.

6. Sulikowski M. The assessmnet of compensatory mechanisms improving pharyngeal phase of deglutition after partial laryngectomy. Otolaryngol Pol 2001; 55(2):153-9.

7. Apostolopoulos K, Samaan R, Labropoulou E. Experience with vertical partial laryngectomy with special reference to laryngeal reconstruction with cervical fascia. J Laryngol Otol 2002;116(1):1923

8. Cooley $\mathrm{M}$ et al. Discrepancies in frozen sectional mucosal margin tissue in laryngeal squamous cell carcinoma. Head Neck 2002; 24(3):262-7.

9. Yilmaz T, Turan E, Gürsel B, Onerci M, Kaya S. Positive surgical margins in cancer of the larynx. Eur Arch Othorhinolaryngol 2001; 258(4):188-91. 